\title{
An audit to evaluate the use of nutrition screening tool in the National Spinal Injury Centre in Stoke Mandeville Hospital, Buckinghamshire Hospitals NHS Trust
}

\author{
S. S. Wong ${ }^{1}$, F. Derry ${ }^{2}$, K. Sherrington ${ }^{2}$ and G. Gonzales ${ }^{2}$ \\ ${ }^{1}$ Department of Nutrition and Dietetics, Stoke Mandeville Hospital, Aylesbury, UK and ${ }^{2}$ National Spinal Injury Centre, \\ Stoke Mandeville Hospital, Aylesbury, UK
}

Malnutrition continues to be an important healthcare problem, which is still under-recognized and under-treated. Patients admitted to hospital should be nutritionally screened and monitored regularly. The National Institute for Health and Clinical Excellence has estimated that only $30 \%$ of patients were screened on admission to hospital ${ }^{(1)}$. The Spinal Nutrition Screening Tool (SNST; Bearne, personal communication) developed in Salisbury has been used for nutritional screening in the National Spinal Injury Centre (NSIC) since 2004. There are limited data to date relating to the use of a nutrition screening tool in patients with spinal cord injuries. The aims of the present audit were to: assess the current use of SNST in the NSIC; record an anthropometric measurement of BMI, albumin levels and nutrient intake using a food record chart. This audit was conducted from May and June 2008. The medical notes of eighty-one patients aged between 18 and 80 years, who had been admitted not less than $72 \mathrm{~h}$ previously, on five spinal wards were examined by nurses and a dietitian. A completed SNST form was present in $60.4 \%$ of patients' records. At the time of audit $47 \%$ patients were found at moderate risk of undernutrition (SNST score $>10$ ) and $8.2 \%$ were at high risk of undernutrition (SNST score $>15$ ), $40 \%$ of patients had a BMI $<20 \mathrm{~kg} / \mathrm{m}^{2}, 15 \%$ of patients were found to have a hypoalbuminaemia (albumin $<30 \mathrm{~g} / \mathrm{l}$ ) and $25 \%$ of patients were found to have eaten less than half their meal. Patients who are at high risk of undernutrition (SNST score $>15$ ) were found to have a significant lower albumin level (SNST $>15,25.5 \mathrm{~g} / 1$. SNST $<10,35.5 \mathrm{~g} / \mathrm{l} ; P=0.003)$. However, no differences were found in BMI $\left(\mathrm{SNST}>15,22.3 \mathrm{~kg} / \mathrm{m}^{2} v\right.$. SNST $\left.<10,22.2 \mathrm{~kg} / \mathrm{m}^{2} ; P=0.68\right)$ when compared with well-nourished patients.

The present audit found the compliance of nutrition screening in NSIC is low $(<75 \%)$ and it varies between wards. Further training and updates on nutrition screening to encourage ward staff to use and complete the SNST screening and take responsibility for nutrition is critical. The introduction of training on the use of the nutrition screening tool for all clinical staff is proposed to increase the use of SNST. Auditing the barriers of nutrition screening in NSIC and follow-up studies of the prevalence of malnutrition and its clinical outcomes in patients with spinal cord injuries in UK spinal injury units are proposed.

1. National Institute for Health and Clinical Excellence (2006) Nutrition Support in Adults: Oral Nutrition Support, Enteral Tube Feeding and Parenteral Nutrition. London: NICE. 